\title{
ВНУТРЕННИЙ КОНТРОЛЬ КАЧЕСТВА СТОМАТОЛОГИЧЕСКОЙ ПОМОЩИ В ПОВЫШЕНИИ ЭФФЕКТИВНОСТИ САНАЦИИ ПОЛОСТИ РТА У СОТРУДНИКОВ ОРГАНОВ ВНУТРЕННИХ ДЕЛ
}

\author{
(C) Иорданишвили А.К. ${ }^{1,2}$, Кевлова Е.В. ${ }^{3}$, Зайцев В.В. ${ }^{3}$ \\ ${ }^{1}$ Северо-Западный государственный медицинский университет им. И.И. Мечникова, \\ Санкт-Петербург; ${ }^{2}$ Военно-медицинская академия им. С.М. Кирова, Санкт-Петербург; \\ ${ }^{3}$ поликлиника № 1 Медико-санитарной части Министерства внутренних дел Российской Федерации \\ по Санкт-Петербургу и Ленинградской области, Санкт-Петербург \\ E-mail: senyagolovko@mail.ru
}

\begin{abstract}
Внедрена в работу стоматологического отделения ведомственного амбулаторно-поликлинического учреждения методика внутреннего контроля качества медицинской помощи при оценке эффективности проведения у аттестованных сотрудников органов внутренних дел санации полости рта и эндодонтического лечения осложненных форм кариеса. Ежегодно, для визуальной оценки качества санации полости рта и выявления ее дефектов осматривалось 240 чел., которые были разделены с учетом возраста на 2 группы исследования: молодого (19-39 лет) и среднего (40-57 лет) возраста. Одновременно с помощью лучевых методов исследования оценивалось 10 случаев эндодонтического лечения пульпита и 10 случаев эндодонтического лечения периодонтита на предмет качества пломбирования каналов корней зубов. Трехлетнее наблюдение за результатами внедрения контроля качества медицинской помощи позволило объективно установить повышение эффективности проводимых стоматологических лечебно-профилактических мероприятий в рамках ежегодной диспансеризации на 29,2\% у молодых людей и на 34,2\% у лиц среднего возраста, по сравнению с показателями, полученными в начальном периоде проведения исследования, а также улучшение качества пломбирования каналов корней зубов при осложненном кариесе.
\end{abstract}

Ключевые слова: санация полости рта, внутренний контроль качества медицинской помощи, кариес зуба, пульпит, заболевания тканей пародонта.

\section{INTERNAL CONTROL OF THE DENTAL CARE QUALITY IN IMPROVING EFFICIENCY OF ORAL CAVITY SANATATION IN INTERNAL AFFAIRS EMPLOYEES Iordanishvili A.K. ${ }^{1,2}$, Kevlova E.V. ${ }^{3}$,Zaitsev V.V. ${ }^{3}$}

${ }^{1}$ I.I. Mechnikov North-West State Medical University, St. Petersburg; ${ }^{2}$ S.M. Kirov Military Medical Academy, St. Petersburg; ${ }^{3}$ Polyclinic N 1 of Medico-Sanitary Department of Ministry of Internal Affairs of Russia for St. Petersburg and Leningrad Region, St. Petersburg

A method for internal quality control of medical care was implemented in the work of the dental department of a departmental outpatient clinic in assessing the effectiveness of oral care and endodontic treatment of complicated forms of caries in certified internal affairs employees. Every year, 240 people were examined for visual assessment of the quality of the oral cavity sanation and detection of its defects, which were divided by age into two study groups: young (19-39 years) and middle (4057 years) age. At the same time, 10 cases of endodontic treatment of pulpitis and 10 cases of endodontic treatment of periodontitis were evaluated with the help of radiotherapy methods for the quality of root canal filling. The three-year observation of the results of introducing the quality control of medical care made it possible to objectively establish an increase in the effectiveness of ongoing dental treatment and prophylactic measures in the annual medical examination by $29.2 \%$ in young people and $34.2 \%$ in middle-aged people, compared to the figures obtained in the initial period of the study, as well as improving the quality of root canal filling with complicated caries.

Keywords: sanation of an oral cavity, internal quality control of a medical care, tooth caries, pulpitis, diseases of tissues of the parodont.

Исследованиями многих ученых и клиницистов показано, что у лиц, находящихся в период их профессиональной деятельности под динамическим медицинским наблюдением или диспансеризаций, стоматологическое здоровье при выходе их на заслуженный отдых, то есть в пожилом и старческом возрасте, значительно выше, чем у лиц, получавших в течение их профессиональной деятельности стоматологическую помощь по обращаемости $[1,3,6,9]$. В ряде публикаций установлено, что повышение контроля над качеством стоматологической помощи в лечебнопрофилактических учреждениях существенно повышает ее результативность и эффективность [2, $4,7,8]$. Аттестованные сотрудники внутренних дел ежегодно проходят диспансеризацию, санируют полость рта [5]. В то же время до сих пор не проводились исследования, позволяющие оценить качество проводимых им санационных мероприятий по сохранению стоматологического здоровья, в рамках ежегодной диспансеризации. 
Это и составило цель настоящего клинического исследования.

Цель исследования: путем осуществления внутреннего контроля за санацией полости рта аттестованным сотрудникам органов внутренних дел повысить эффективность проводимых им стоматологических лечебно-профилактических мероприятий в рамках ежегодной диспансеризации.

\section{МАТЕРИАЛЫ И МЕТОДЫ ИССЛЕДОВАНИЯ}

Клиническое исследование состояло из двух этапов и проводилось в течение трех лет. В первый год исследования врачей-стоматологов не предупреждали о контроле качества стоматологической помощи. На первом этапе путем осмотра полости рта аттестованным сотрудникам органов внутренних дел, при участии заведующего стоматологическим отделением ведомственного лечебно-профилактического учреждения, выявляли дефекты санации полости рта. На втором этапе исследования, путем выборочного контроля, по данным первичной медицинской документации, выбирались 10 случаев эндодонтического лечения пульпита и 10 случаев эндодонтического лечения периодонтита, пациенты приглашались на контрольный осмотр, и с помощью лучевых методов исследования или рентгенологического контроля оценивалось качество пломбирования каналов корней зубов. Во второй и третий годы исследования врачи-стоматологи знали о последующем контроле над качеством выполненной им санации полости рта. Внутренний контроль над качеством санации полости рта во второй и третий год ис- следования был проведен по описанной ранее методике.

Ежегодно для визуальной оценки качества санации полости рта и выявления ее дефектов осматривалось 240 чел., которые были разделены с учетом возраста на 2 группы исследования: молодого (19-39 лет) и среднего (40-57 лет) возраста. Таким образом, за весь период обследования было осмотрено и оценено качество санации у 720 аттестованных сотрудников органов внутренних дел, а также проведена оценка качества пломбирования каналов корней зубов при лечении пульпита и периодонтита, у 120 аттестованных сотрудников органов внутренних дел. Полученный в результате эпидемиологического исследования цифровой материал был обработан на ПК с помощью специализированного пакета для статистического анализа - «Statistica for Windows, v. 6.0», с использованием критерия Стьюдента. Различия между сравниваемыми группами считались достоверными при $\mathrm{p} \leq 0,05$. Случаи, когда значения вероятности показателя «р» находились в диапазоне от 0,05 до 0,10 , расценивали как «наличие тенденции».

\section{РЕЗУЛЬТАТЫ ИССЛЕДОВАНИЯ И ИХ ОБСУЖДЕНИЕ}

Анализ состояния органов и тканей полости рта у аттестованных сотрудников органов внутренних дел молодого и среднего возраста позволил выявить дефекты санации полости рта в первый год исследования соответственно у 35,85\% (43 чел.) и 40,83\% (49 чел.) из числа осмотренных (рис. 1).

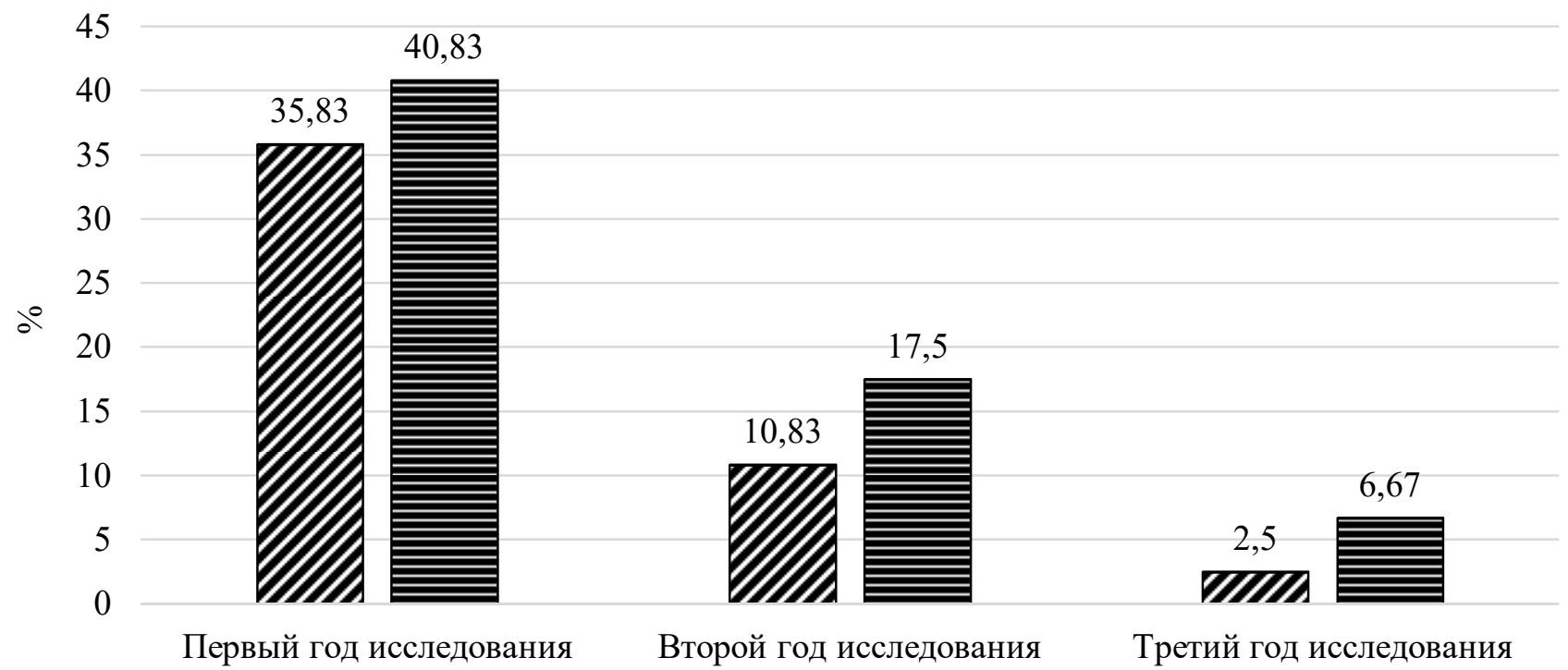

$\boldsymbol{\nabla}$ Молодой возраст $\boldsymbol{\Xi}$ Средний возраст

Рис. 1. Количество пациентов молодого и среднего возраста с дефектами санации полости рта при трехлетнем наблюдении за ее качеством (\%). 
Третий год наблюдения

$\approx$

Второй год наблюдения

Первый год наблюдения

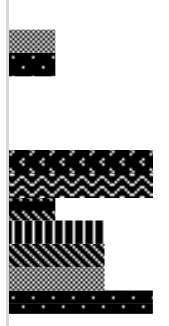

曲曲,

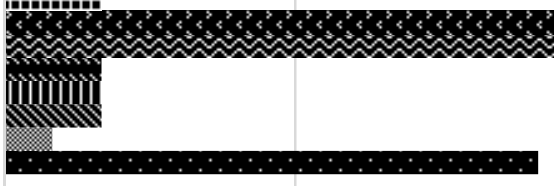

$\% 0$

5

10

15

\#: Патология слизистой оболочки полости рта

\& Локализованный гингивит

* Локализованный пародонтит

III Зубные отложения

а) Клиновидные дефекты

- Гиперестезия зубов

$\mathbf{\$}$ Не удаленные корни зуба

- Кариес

Третий год наблюдения

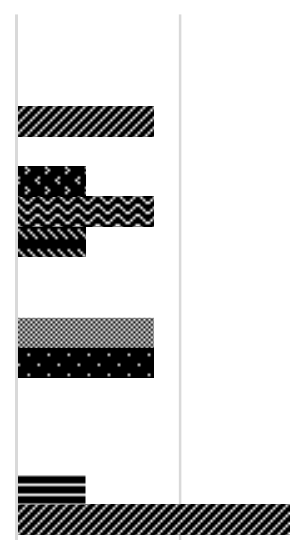

Второй год наблюдения

Первый год наблюдения
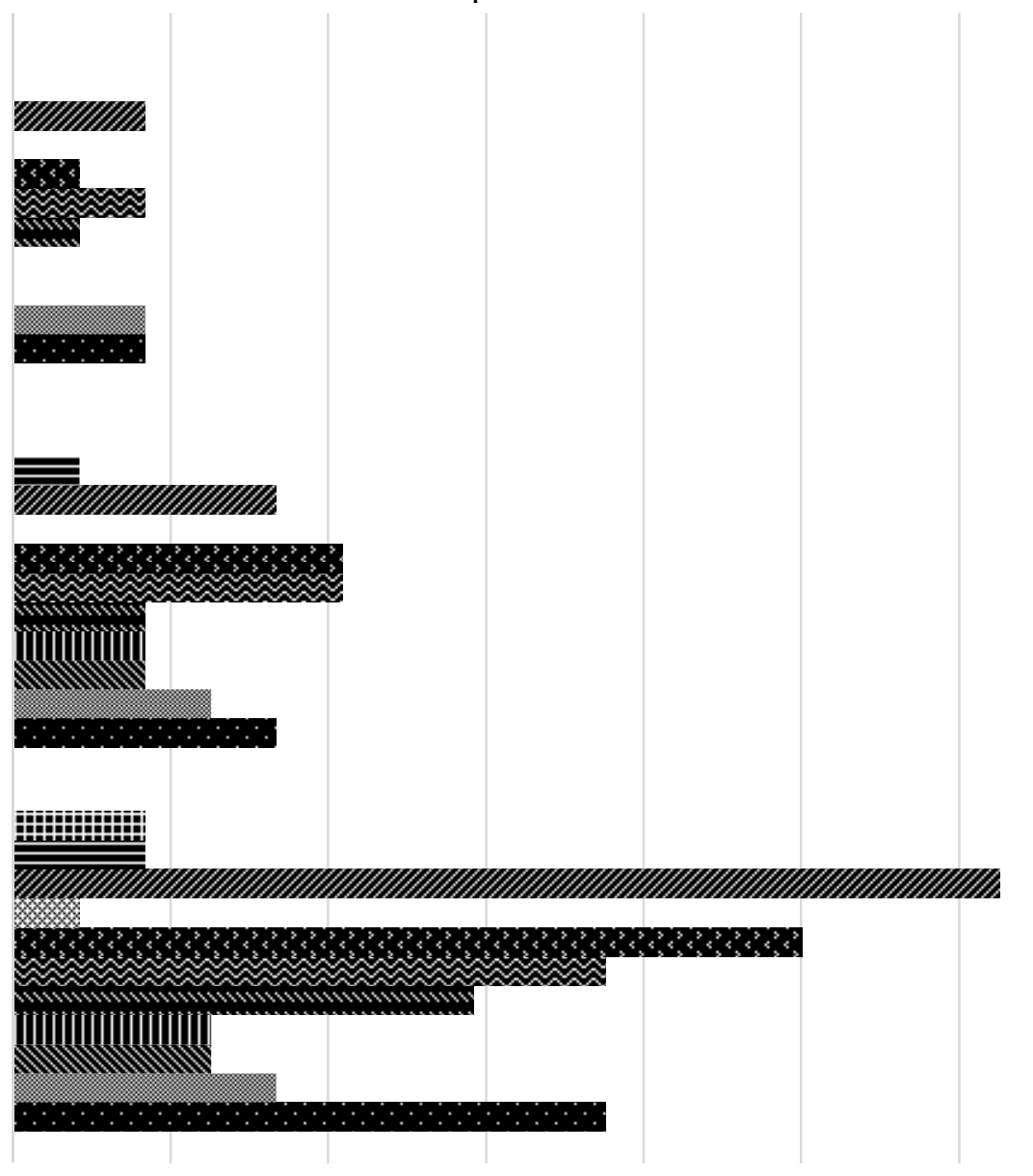

$$
\% 0 \quad 2 \quad 4
$$

$\begin{array}{ll}6 & 8\end{array}$

10

12

14

* Патология слизистой оболочки полости рта

= Кариес корня зуба

z Хронический генерализованный пародонтит

a Локализованный пародонтит

б) Гиперестезия зубов

Остеомиелит челюсти

× Локализованный гингивит

II Зубные отложения

Рис. 2. Частота встречаемости выявленных дефектов санации полости рта у пациентов молодого (а) и среднего (б) возраста при трехлетнем наблюдения за ее качеством (\%). 


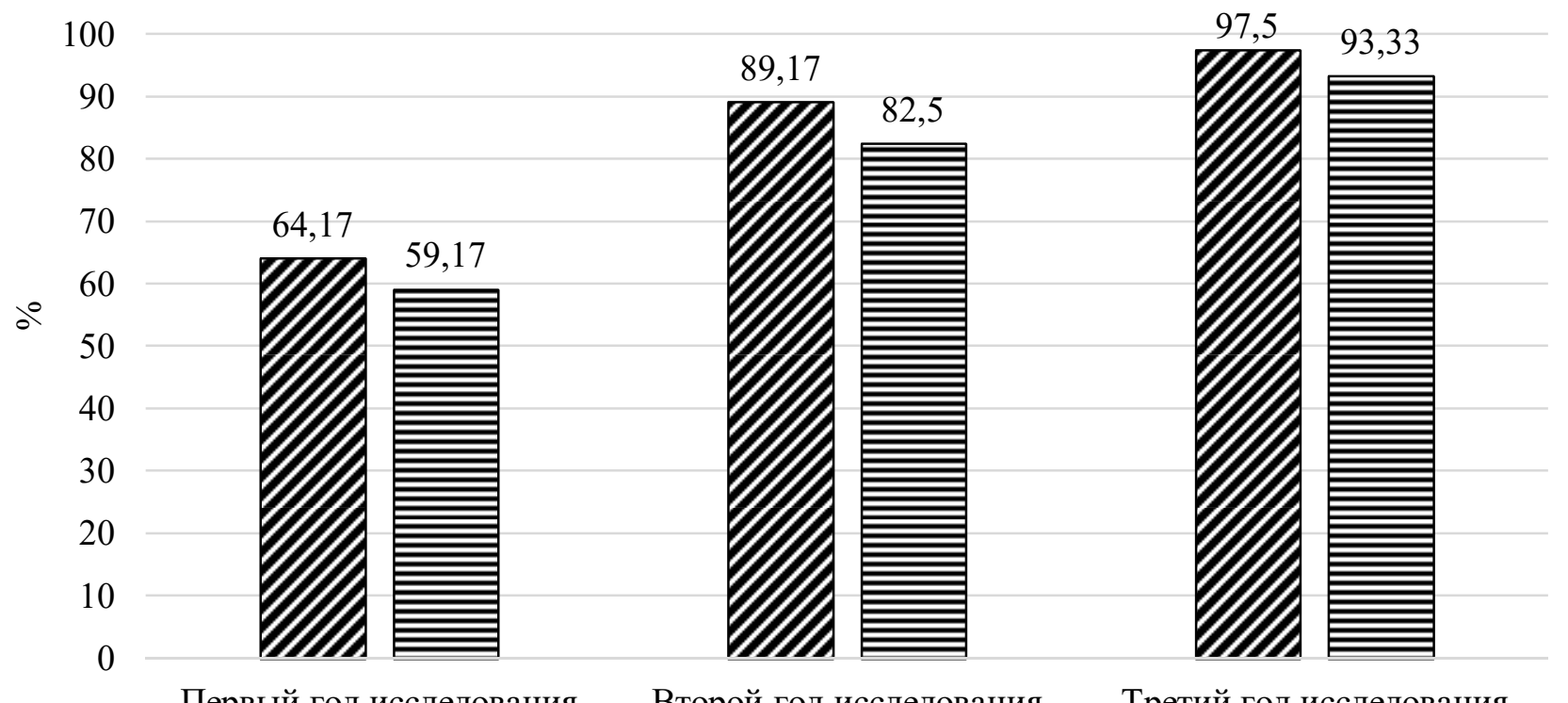

Первый год исследования Второй год исследования

Третий год исследования

\section{चМолодой возраст вСредний возраст}

Рис. 3. Эффективность санации полости рта у аттестованных сотрудников органов внутренних дел молодого и среднего возраста при наблюдении за ее качеством в течение трехлетнего периода (\%).

У лиц молодого возраста после завершения санации полости рта диагностированы: кариес зубов (11 чел.), клиновидные дефекты (1 чел.), локализованный гингивит и пародонтит у 19 и 17 чел., не удаленные корни зубов (хронический периодонтит) - у 2 чел., а также отложения зубного камня - у 2 чел., гиперестезия зубов - у 2 чел., заболевания слизистой оболочки полости рта (метеорологический хейлит, хроническая трещина красной каймы нижней губы) - 2 чел. (рис. 2). У лиц среднего возраста, при осуществлении внутреннего контроля качества медицинской помощи, также были диагностированы дефекты санации полости рта, а именно кариес зубов (9 чел.), кариес корня зуба (1 чел.), клиновидные дефекты (4 чел.), локализованный гингивит и пародонтит соответственно у 9 и 17 чел., хронический генерализованный пародонтит (ХГП) - у 15 чел., патология слизистой оболочки полости рта в виде хронической трещины красной каймы нижней губы и простой формы лейкоплакии языка (2 чел.), не удаленные корни зубов (хронический периодонтит - у 3 чел., а также отложения зубного камня - у 3 чел., гиперестезия зубов - у 27 чел., хронический остеомиелит альвеолярного отростка верхней челюсти - у 1 чел. (рис. 2).

При контроле качества медицинской помощи в последующие два года клинического исследования количество дефектов санации полости рта значительно уменьшилось $(\mathrm{p} \leq 0,05)$. Дефекты санации полости рта на второй год исследования были определены у 10,83\% среди лиц молодого возраста и у 17,5\% - среди лиц средней возрастной группы (рис. 1). Было установлено, что у лиц молодого возраста на второй год исследования, были диагностированы: кариес зуба у 3 чел., клиновидные дефекты - у 2 чел., гиперестезия зубов - у 1 чел., локализованный гингивит и пародонтит - соответственно у 3 и 3 чел., не удаленные корни зубов (хронический периодонтит) - у 2 чел., а также отложения зубного камня - у 1 чел. (рис. 2). У лиц среднего возраста на второй год проведения исследования, при осуществлении внутреннего контроля качества медицинской помощи, были диагностированы: кариес зубов (5 чел.), кариес корня зуба (1 чел.), клиновидные дефекты (3 чел.), локализованный гингивит и пародонтит - соответственно у 5 и 5 чел., хронический генерализованный пародонтит (ХГП) - у 4 чел., не удаленные корни зубов (хронический периодонтит) - у 2 чел., а также отложения зубного камня - у 2 чел. (рис. 2). Так, у лиц молодого и среднего возраста на следующий год уменьшилась неэффективность санации полости рта соответственно на $25 \%$ и $23,33 \%(\mathrm{p} \leq 0,01)$ по сравнению с результатами, полученными на первом году проведения работы (рис. 3).

В третий год исследования количество дефектов санации полости рта вновь уменьшилось. Они выявлены у 2,5\% лиц молодого возраста и у $6,67 \%$ - среди лиц средней возрастной группы (рис. 1). Так, у лиц молодого и среднего возраста, на третий год исследования уменьшилась неэффективность санации полости рта соответственно на $29,16 \%$ и $34,16 \%(\mathrm{p} \leq 0,01)$ по сравнению с результатами, полученными на первом году проведения работы (рис. 3). У лиц молодого возраста на третий год исследования были диагностированы: кариес зуба у 1 чел., клиновидные дефекты у 1 чел., локализованный гингивит - у 1 чел. 
(рис. 2). У лиц среднего возраста на третий год проведения исследования, при осуществлении внутреннего контроля качества медицинской помощи, количество диагностированных дефектов санации также существенно уменьшилось. Были выявлены: кариес зубов (1 чел.), клиновидные дефекты (2 чел.), локализованный гингивит и пародонтит - соответственно у 2 и 1 чел., хронический генерализованный пародонтит (ХГП) у 2 чел. (рис. 2).

Молодой возраст. Периодонтиты, третий год

Молодой возраст, пульпиты, третий год

Молодой возраст, периодонтиты второй год

Молодой возраст, пульпитты, второй год

Молодой возраст, периодонтиты, первый год

Молодой возраст пульпиты, первый год
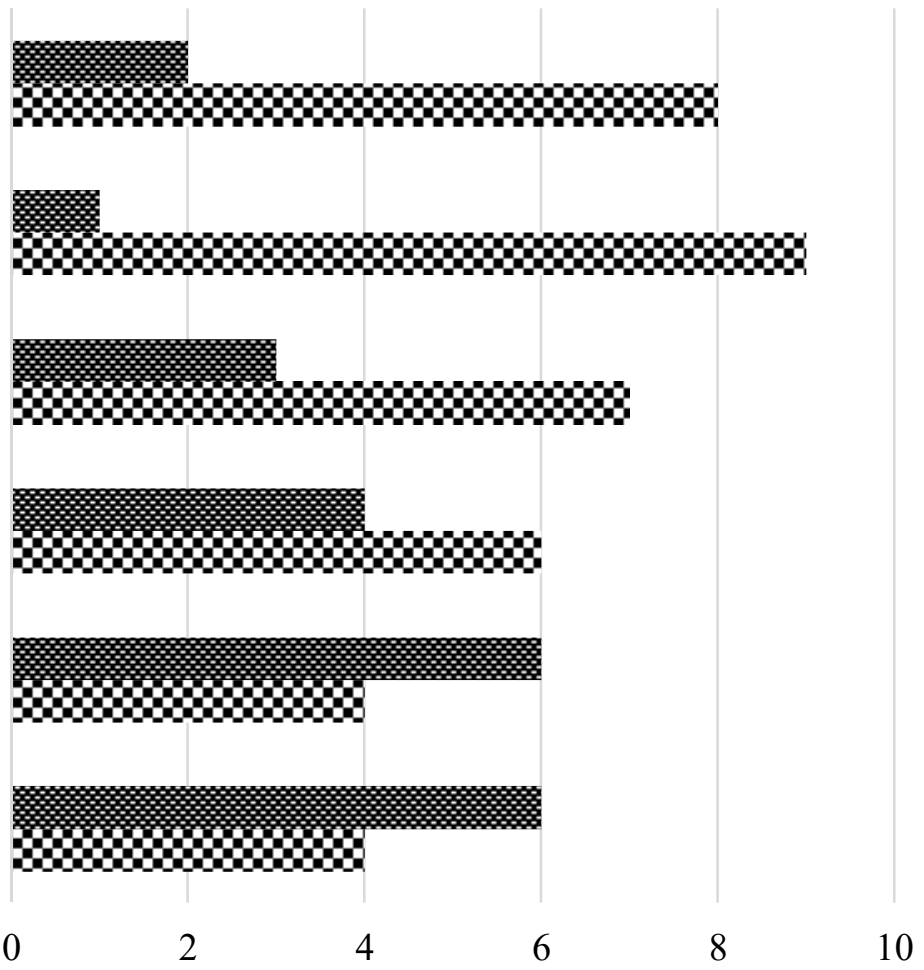

Некачественное пломбирование каналов корней зубов

a Качественное пломбирование каналов корней зубов

a)

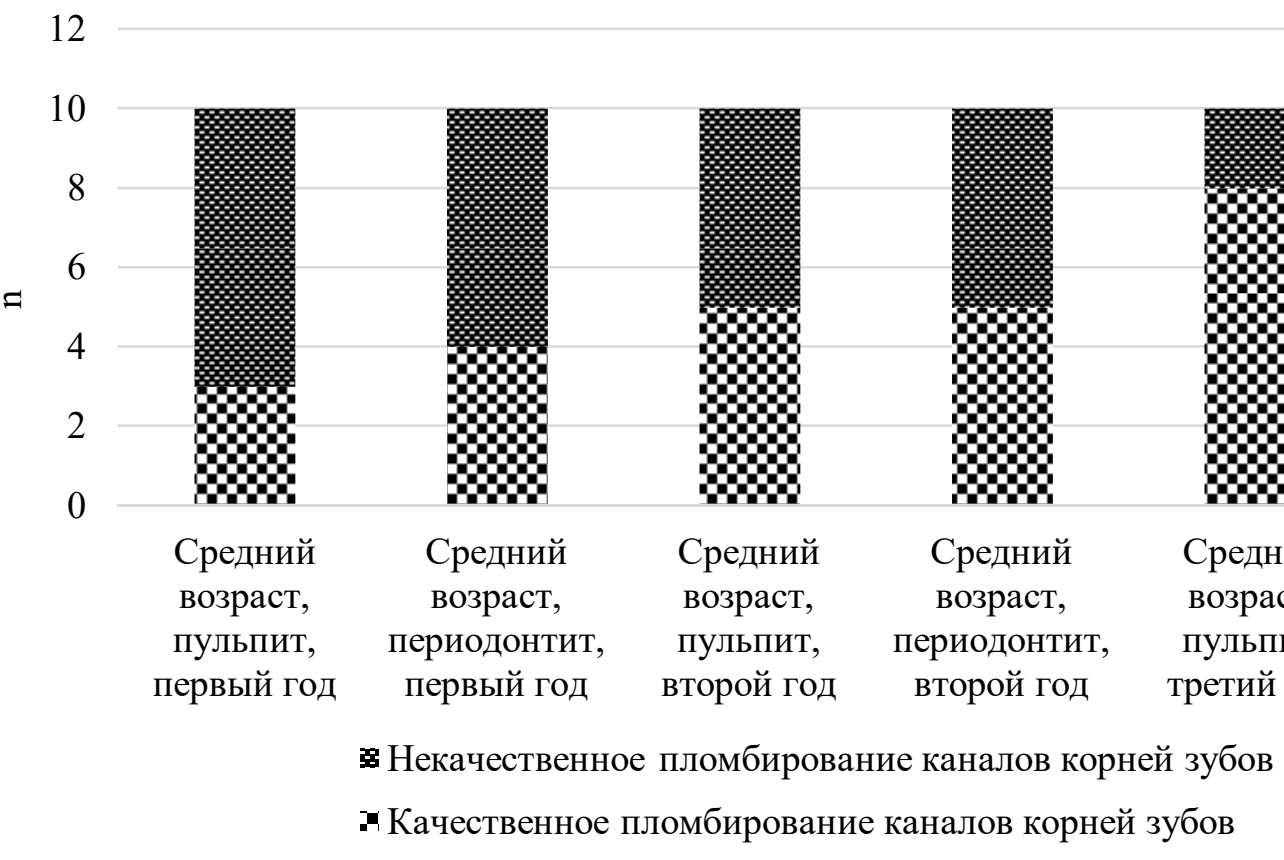

б)

Рис. 4. Оценка качества эндодонтического лечения осложненного кариеса у аттестованных сотрудников органов внутренних дел молодого (а) и среднего (б) возраста при наблюдении за ее качеством в течение трехлетнего периода, (n). 
Таким образом, внутренний контроль медицинской помощи позволил существенно повысить эффективность плановой санации органов и тканей полости рта у аттестованных сотрудников органов внутренних дел молодого и среднего возраста соответственно на 29,2 и $34,2 \%$, по сравнению с показателями, полученными в начальном периоде проведения работы.

Изучение качества эндодонтического лечения зубов при осложненных формах кариеса, благодаря проведению внутреннего контроля с использованием объективных методов лучевого исследования, существенно повысилось, как при лечении пульпита, так и при лечении периодонтита (рис. 4).

Врачей стоматологов-терапевтов, допускающих большое количество дефектов при санации полости рта и эндодонтическом лечении зубов, направляли на тематические усовершенствования или мастер-классы, а при неэффективности этих мероприятий - на аттестационную комиссию для определения в процессе их аттестации квалификационной категории по специальности «Стоматология терапевтическая», что позволило улучшить результаты их работы.

Таким образом, проведенное клиническое исследование показало, что диагностические и лечебно-профилактические мероприятия при проведении плановой санации полости рта у аттестованных сотрудников органов внутренних дел в настоящее время выполняются не в полном объеме и не всегда эффективно. Для повышения эффективности диагностических и лечебнопрофилактических мероприятий, выполняемых при санации полости рта у аттестованных сотрудников органов внутренних дел, целесообразно заведующему стоматологическим отделением ведомственного амбулаторно-поликлинического учреждения проводить контролирующие мероприятия за качеством санации путем выборочного контрольного осмотра санированных сотрудников органов внутренних дел.

\section{ЛИТЕРАТУРА}

1. Иорданишвили А.К., Салманов И.Б. Диагностика осложненных форм кариеса зубов: ремарки к выполнению стандарта оказания специализированной медицинской помощи // Эндодонтия today. 2015. - № 4. - С. 18-21.

2. Иорданишвили А.К., Салманов И.Б., Кльпина Г.Н., Зайцев В.В., Андреева О.Д. Опыт внедрения системы оценки качества медицинской помощи в отделениях терапевтической стоматологии ведомственных организаций при консервативном лечении пульпита и периодонтита // Медицинский вестник МВД. - 2015. - Т. LXXVIII, № 5. C. 57-64.

3. Иорданишвили А.К., Салманов И.Б., Сериков А.А. Медицинская визуализация в оценке стандарта оказания эндодонтической помощи при заболеваниях пульпы зуба // Вестник Российской Военномедицинской академии. - 2015. - № 4 (52). С. $38-42$.

4. Иорданишвили А.К., Салманов И.Б., Сериков А.А. Осложненные формы кариеса зубов как причина обращаемости за медицинской помощью военнослужащих и гражданских лиц // Курский научнопрактический вестник «Человек и его здоровье». 2015. - № 3. - С. 35-40.

5. Иорданишвили А.К., Солдаткина А.С. Заболевания органов и тканей полости рта у лиц молодого возраста // Институт стоматологии. - 2015. № 3 (68). - С. 38-40.

6. Иорданишвили А.К., Салманов И.Б., Кльпина Г.Н., Сериков А.А.. Оценка стандарта оказания эндодонтической помощи при заболеваниях периодонта зуба // Российский стоматологический журнал. 2015. - Т. 19, № 6. - С. 24-27.

7. Иорданишвили А.К., Салманов И.Б., Старченко В.И., Быков Н.И. Оценка эффективности эндодонтической помощи при патологии периодонта // Кубанский научный медицинский вестник. 2016. - № 1 (156). - С. 57-62.

8. Иорданишвили А.К., Солдаткина А.С., Кльпина Г.Н., Слугина А.Г. Санация полости рта у курсантов высших военных учебных учреждений и пути повышения ее эффективности // Стоматология детского возраста и профилактика. - 2016. T. XV, № 1 (56). - C. 77-80.

9. Perls T., Kunkel L.M., Puca A.A. The genetics of exceptional human longevity // J. Amer. Geriat. Soc. 2002. - Vol. 50, N 2. - P. 359-368. 